\title{
POTENCIAL GENÉTICO DA CULTIVAR DE MILHO BR 5011-SERTANEJO NOS TABULEIROS COSTEIROS DO NORDESTE BRASILEIRO1
}

\author{
HELIO WILSON LEMOS DE CARVALHO², MARIA DE LOURDES DA SILVA LEAL ${ }^{3}$, \\ MANOEL XAVIER DOS SANTOS ${ }^{4}$ e CLESO ANTONIO PATTO PACHECO ${ }^{4}$
}

\begin{abstract}
RESUMO - Cinco ciclos de seleção entre e dentro de progênies de meios-irmãos foram realizados na cultivar de milho BR 5011-Sertanejo, nos municípios de Neópolis (1991 e 1992), Neópolis e Umbaúba (1993), Lagarto (1994) e Neópolis, Lagarto e Cruz das Almas (1995), localizados nos tabuleiros costeiros do Nordeste brasileiro, visando à obtenção de uma cultivar mais produtiva e mais bem adaptada às condições edafoclimáticas da região. As progênies foram avaliadas em látice 14x14, com duas repetições. As recombinações foram realizadas dentro do mesmo ano agrícola do teste, de modo a se obter um ciclo por ano. A variabilidade genética da cultivar BR 5011-Sertanejo permaneceu praticamente a mesma nos ciclos VI, VII e IX, quando a seleção foi efetuada em um só local. Nos ciclos VIII e X, realizados em mais de um local, detectou-se redução dessa variabilidade pelo fato de as estimativas obtidas estarem menos influenciadas pela interação progênies x locais, o que evidencia a importância de se realizar a seleção em mais de um local, para melhorar a eficiência do processo seletivo e obter estimativas mais consistentes dos componentes da variância genotípica. O ganho médio estimado por ciclo de seleção foi de $12,68 \%$. A possibilidade de ganho com a seleção, a alta variabilidade genética apresentada pela cultivar e as elevadas médias de produtividade das progênies indicam o grande potencial dessa população na continuidade do programa de melhoramento.
\end{abstract}

Termos para indexação: seleção, progênies de meios-irmãos, variação genética, fatores edáficos, fatores climáticos, métodos de melhoramento, melhoramento de plantas.

GENETIC POTENTIAL OF BR 5011-SERTANEJO MAIZE CULTIVAR

IN THE COASTAL PLAINLANDS OF THE NORTHERN REGION OF BRAZIL

ABSTRACT - Five selection cycles were carried among and within half-sib progenies on the cultivar BR 5011-Sertanejo in the Counties of Neópolis (1991 and 1992), Neópolis and Umbaúba (1993), Lagarto (1994) and Neópolis, Lagarto and Cruz das Almas (1995), located in the Coastal Plainlands of the Northern region of Brazil. The study aimed to obtain a more yielding and well adapted cultivar of maize to the soil and climatic conditions of this region. The progenies were evaluated in lattice $14 \times 14$ with two replications. Recombinations of the outstanding progenies were processed within the same year in order to get one cycle per year. The magnitude of the genetic variability of the BR5011Sertanejo cultivar was approximately the same in the cycles VI, VII and IX, conducted in one location. However, a reduction of this variability was observed in the cycles VIII and X, performed in more than one locality, since the estimatives obtained were less influenced by the interaction progeny $\mathrm{x}$ local, showing the importance of the selection in more than one environment, to increase the efficiency of the process and to obtain more accurate estimates of the genotypic variances. In relation to year yield the average gain estimated per selection cycle was $12.68 \%$ which associated to the high genetic variability presented by the cultivar and to the high average of progenies productivity indicates its potential for the continuation of the breeding program.

Index terms: selection, half-sib progenies, genetic variation, edaphic factors, climatic factors, breeding methods, plant breeding.

\footnotetext{
${ }^{1}$ Aceito para publicação em 15 de junho de 1999.

${ }^{2}$ Eng. Agrôn., M.Sc., Embrapa-Centro de Pesquisa Agropecuária dos Tabuleiros Costeiros (CPATC), Av Beira-Mar, 3.250, Caixa Postal 44, CEP 49001-970 Aracaju, SE.E-mail: helio@cpatc.embrapa.br
}

\footnotetext{
${ }^{3}$ Eng. Agrôn., Embrapa-CPATC.

E-mail: lurdinha@cpatc.embrapa.br

${ }^{4}$ Eng. Agrôn., M.Sc., Embrapa-Centro Nacional de Pesquisa de Milho e Sorgo (CNPMS), Rod. MG 424, km 65, Caixa Postal 151, CEP 35701-970 Sete Lagoas, MG. E-mail: xavier@cnpms.embrapa.br, cleso@cnpms.embrapa.br
} 


\section{INTRODUÇÃO}

O desenvolvimento de novas cultivares de milho, bem adaptadas e de alta produtividade, é de suma importância para incrementar a melhoria de rendimento da atividade do agricultor. Entre os vários métodos de seleção intrapopulacional utilizados para aumentar a freqüência dos alelos favoráveis nas populações, o de seleção entre e dentro de famílias de meios-irmãos tem-se mostrado eficiente, permitindo a obtenção de progressos de forma mais rápida, pela possibilidade de realização de um ciclo por ano. A análise dos dados do teste de progênies permite estimar a variância genética aditiva na população-base, e, em conseqüência, verificar quais as chances de êxito na seleção.

O primeiro trabalho relatando resultados satisfatórios, utilizando esse método, foi descrito por Paterniani (1967), que obteve um progresso médio de $13,6 \%$ por ciclo, após três ciclos de seleção para produtividade, utilizando a população de milho Dente Paulista. Webel \& Lonquist (1967), citados por Paterniani (1968), obtiveram progresso médio de 9,4\% por ciclo, após quatro ciclos de seleção para produtividade na população de milho Hays Golden. Esse resultado foi considerado pelo autor como satisfatório, em razão da uniformidade do milho utilizado. Bons resultados também foram encontrados por Cunha (1976), para o composto HV-1, o qual obteve um progresso médio por ciclo de $8,15 \%$, com três ciclos de seleção para produtividade. Dados mais recentes obtidos por Carvalho et al. (1994, 1995, 1998a) revelaram progressos médios de $10,60 \%$, $17,66 \%$ e $12,76 \%$, por ciclo de seleção, após três ciclos de seleção para produtividade nas cultivares BR 5028, BR 5033 e BR 5011, respectivamente. Carvalho et al. (1998b) obtiveram um progresso de $29,8 \%$, por ciclo, após quatro ciclos de seleção para a produtividade, na cultivar BR 5028. Os autores, neste último trabalho, chamam a atenção para o fato de os ganhos obtidos nos ciclos VI e VII, os quais foram de $53,0 \%$ e $31,6 \%$, respectivamente, estarem influenciados pela interação progênies $\mathrm{x}$ locais, por terem sido realizados em um só local. Os ganhos obtidos nos ciclos VIII e IX, na média de dois locais, foram de $24,4 \%$ e $11,3 \%$, respectivamente.
No tocante à variância genética aditiva para a produção de grãos, Ramalho (1977) efetuou um levantamento envolvendo 30 ensaios realizados no Brasil até 1976, encontrando valores que oscilaram de $41,0(\mathrm{~g} / \mathrm{planta})^{2}$ a $758,0(\mathrm{~g} / \mathrm{planta})^{2}$, com média de $420,0(\mathrm{~g} / \mathrm{planta})^{2}$. Lima (1977) obteve valores de 438,83 (g/planta $)^{2}, 377,81$ (g/planta $)^{2}$ e 344,32 (g/planta $)^{2}$, observando que essas estimativas não decresceram significativamente após a realização de três ciclos de seleção. Miranda Filho (1974) mostrou também a potencialidade de sete populações para a formação do Composto ESALQ PB-1. Posteriormente, com progênies de meios-irmãos, obteve estimativa bastante semelhante na avaliação de dois ciclos de seleção, concluindo que haveria êxito em se obter uma população bastante melhorada, haja vista a variabilidade genética aditiva existente em todos os caracteres estudados. Aguiar (1986) e Pacheco (1987) detectaram valores que oscilaram entre $118,4$ (g/planta $)^{2}$ e 750,0 (g/planta $)^{2}$, em média de 296,6 (g/planta $)^{2}$, com base na avaliação de 400 progênies da população CMS-39, nos ciclos original e primeiro. Esses valores são compatíveis com os relatados por Hallauer \& Miranda Filho (1988), cujo valor médio de 99 estimativas foi de 469,1 (g/planta) ${ }^{2}$. Valores mais altos foram encontrados por Lordello (1982), com as populações Piranão VD-2 e Piranão VF-1, de 1995,0 (g/planta) ${ }^{2}$ e $1725,0(\mathrm{~g} / \mathrm{planta})^{2}$, respectivamente. Carvalho et al. $(1994,1995,1998$ a) encontraram valores que oscilaram entre $311,2(\mathrm{~g} / \text { planta })^{2}$ e $1.477,7$ (g/planta $)^{2}$, com as cultivares BR 5028, BR 5033 e BR 5011, respectivamente. Carvalho et al. (1998b) encontraram estimativas de $1.827,1$ (g/planta $)^{2} \mathrm{e}$ $1.273,4$ (g/planta) ${ }^{2}$, nos ciclos VI e VII, com a cultivar BR 5028

Conforme pode ser observado, a utilização do método de seleção entre e dentro de progênies de meios-irmãos tem proporcionado bons ganhos com a seleção. Neste estudo, procurou-se obter uma cultivar de milho mais produtiva e mais bem adaptada às condições edafoclimáticas do nordeste brasileiro, em comparação com a cultivar atualmente em uso.

\section{MATERIAL E MÉTODOS}

Introduzida do CIMMYT pela Embrapa-Centro Nacional de Pesquisa de Milho e Sorgo, em 1975, a população 
Pool 21 recebeu a denominação de CMS-11, após ser submetida a um ciclo de seleção massal no ano agrícola de 1976/77. Posteriormente, essa população sofreu dois ciclos de seleção entre e dentro de progênies de irmãos germanos, nos anos agrícolas de 1978/79 e 1979/80. Em 1981/82 foram avaliadas 400 progênies $S_{2}$ obtidas das melhores progênies de irmãos germanos (Gama et al., 1986).

No Nordeste brasileiro, após participar de uma rede de ensaios de competição de cultivares, durante os anos de 1982, 1984 e 1985, essa população mostrou alto potencial de produtividade e características agronômicas desejáveis (Carvalho \& Serpa, 1987), e foi escolhida para ser submetida a um programa de melhoramento intrapopulacional, recebendo a denominação de BR 5011-Sertanejo. Trata-se de uma cultivar de polinização aberta, com 62 dias para atingir a floração feminina. A altura média das plantas está entre $2,30 \mathrm{~m}$ e $2,80 \mathrm{~m}$ e a altura da inserção da primeira espiga entre $1,20 \mathrm{~m}$ e $1,50 \mathrm{~m}$. Possui bom empalhamento de espigas e os seus grãos são semiduros, de coloração amarela intensa. No período de 1985 a 1987 passou por três ciclos de seleção entre e dentro de progênies de meios-irmãos (Carvalho et al., 1998a). Entre 1988 e 1990, passou por três ciclos de seleção massal quanto aos caracteres altura de planta e de inserção de primeira espiga, empalhamento, acamamento e quebramento do colmo, e coloração de grãos, no Estado de Sergipe. Avaliada em ensaios de competição de cultivares, em vários ambientes em Sergipe, mostrou boa adaptação e boa estabilidade de produção nos ambientes considerados (Carvalho et al., 1992).

No último ciclo de seleção massal quanto aos caracteres já mencionados, em 1990, foram selecionadas 196 plantas competitivas, prolíficas, bem empalhadas, com baixas alturas de planta e de inserção da primeira espiga, de grãos semiduros e de cor amarelo intenso, para reiniciar o programa de melhoramento, utilizando-se o esquema de seleção entre e dentro de progênies de meios-irmãos.

Este trabalho engloba os ciclos VI e VII, nos anos de 1991 e 1992 no município de Neópolis; o ciclo VIII, em 1993, em Neópolis e Umbaúba; o IX, em 1994, em Lagarto; e o X, em Neópolis, Lagarto e Cruz das Almas, no ano de 1995. À exceção de Cruz das Almas, que está localizado na Bahia, os demais municípios localizam-se na faixa dos tabuleiros costeiros do Nordeste brasileiro, no Estado de Sergipe.

Nos cinco ciclos de seleção, as progênies foram avaliadas em látice simples $14 \times 14$. As parcelas constaram de uma fileira de 5,0 $\mathrm{m}$ de comprimento, com espaçamento de $0,90 \mathrm{~m}$, com um total de 25 plantas por fileira após o desbaste. Todos os ensaios e os campos de recombinação receberam uma adubação de $\mathrm{N}$ e $\mathrm{P}, \operatorname{com} 80 \mathrm{~kg} / \mathrm{ha}$ de $\mathrm{Ne}$
$80 \mathrm{~kg} /$ ha de $\mathrm{P}_{2} \mathrm{O}_{5}$, nas formas de uréia e superfosfato simples, respectivamente. Foi praticada a intensidade de seleção de $10 \%$, tanto entre como dentro das progênies, no mesmo ano agrícola. As progênies selecionadas foram recombinadas em lotes isolados, por despendoamento, sendo as fileiras femininas (despendoadas) representadas pelas progênies selecionadas, e as masculinas, representadas pela mistura das progênies.

Inicialmente, foram realizadas as análises de variância por ensaio, obedecendo-se ao esquema em látice. Nos ciclos com ensaios realizados em mais de um local, procedeu-se análise de variância conjunta agrupada, a partir das médias ajustadas de tratamentos, considerando-se aleatório o efeito de locais. Os locais utilizados constituem uma amostra representativa dos tabuleiros costeiros. Os quadrados médios das análises de variância por local e conjunta foram ajustados para o nível de indivíduos, obtendo-se todas as variâncias nesse nível e expressas em (g/planta $)^{2}$, conforme Vencovsky (1978). Para a estimação dos componentes da variância foram consideradas as esperanças dos quadrados médios para blocos casualizados, usando-se os quadrados médios de tratamentos ajustados e o erro efetivo do látice, conforme metodologia descrita por Vianna \& Silva (1978). Estimou-se o coeficiente de herdabilidade no sentido restrito no nível de média de progênie $\left(h^{2} \mathrm{~m}\right)$ pela relação $\sigma_{\mathrm{p}}^{2} / \sigma^{2} \overline{\mathrm{F}}$, em que $\sigma_{\mathrm{p}}^{2}$ é a variância genética entre progênies de meios-irmãos e $\sigma^{2} \overline{\mathrm{F}}$ é a variância fenotípica entre médias de progênies. O coeficiente de herdabilidade em nível de planta $\left(\mathrm{h}^{2}\right)$ foi estimado pela relação $\sigma_{\mathrm{A}}^{2} / \sigma^{2} \mathrm{P}$, em que $\sigma^{2}{ }_{\mathrm{A}}$ é a variância genética aditiva e $\sigma_{\mathrm{P}}^{2}$ eqüivale à soma das variâncias genotípica entre progênies e fenotípica dentro de progênies, sendo esta última correspondente a $\sigma^{2}{ }_{\mathrm{d}}=10 \sigma^{2}$. O índice de variação (b) é dado pelo quociente $\mathrm{CVg} / \mathrm{CVe}$, em que $C V g=\sqrt{\sigma_{p}^{2} / \bar{x}}$ é o coeficiente de variação genética e CVe é o coeficiente de variação experimental.

A estimativa do progresso genético esperado em cada ciclo de seleção foi feita pela fórmula:

$\triangle \mathrm{g}=\mathrm{i}\left(\left(0,25 \boldsymbol{\sigma}_{\mathrm{A}}^{2} / \sigma_{\overline{\mathrm{F}}}\right)+\mathrm{p}\left(0,75 \sigma_{\mathrm{A}}^{2} / \sigma_{\mathrm{p}}\right)\right)$

sendo $\mathrm{i}=1,755 \mathrm{e} \mathrm{p}=0,5$. Considerou-se também a relação $\sigma_{\mathrm{d}}^{2}=10 \sigma^{2}$ por não se dispor de dados de plantas individuais (Webel \& Lonquist, 1967, citados por Winkler, 1977).

\section{RESULTADOS E DISCUSSÃO}

As evidências amostrais indicam diferenças altamente significativas entre as progênies que 
podem ser obtidas da população-base, em todos os ciclos de seleção, o que evidencia a presença de variabilidade genética entre elas, quanto ao peso das espigas (Tabela 1). Nos ciclos VIII e X obteve-se evidência de interação progênies x locais, o que revela comportamentos diferenciados das progênies em face das variações ambientais. A ocorrência de interação também foi observada por Pacheco (1987) e Carvalho et al. (1994, 1995, 1998a, 1998b). Os coeficientes de variação ambiental foram baixos, e isto indica boa precisão dos ensaios (Pimentel-Gomes, 1978).

O efeito da seleção entre e dentro de progênies de meios-irmãos sobre a produtividade da cultivar BR 5011, durante os cinco ciclos de seleção, pode ser visto na Tabela 2. As produtividades médias obtidas com as 196 progênies avaliadas e com as 20 selecionadas foram superiores a $6.000 \mathrm{~kg} / \mathrm{ha} \mathrm{e} 7.200 \mathrm{~kg} / \mathrm{ha}$ de espigas, respectivamente, o que atesta a alta capacidade produtiva da cultivar BR 5011-Sertanejo. Vale ressaltar que as produtividades médias das progênies avaliadas somente foram inferiores às médias das testemunhas no ciclo VIII. Assim, nota-se que a população correspondente ao ciclo VIII produziu menos que a cultivar BR 106 e o híbrido duplo BR 201, sendo as produtividades relativas a essas testemunhas de $86 \%$ e $88 \%$, respectivamente. As progênies selecionadas

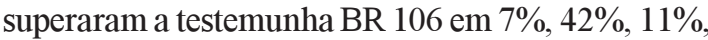
$56 \%$ e $34 \%$, respectivamente, nos ciclos VI, VII, VIII, IX e X. Com relação ao híbrido BR 201, a superioridade foi de $16 \%$, $14 \%$, $31 \%$ e $26 \%$, nos ciclos VII, VIII, IX e X, respectivamente. Tomando-se o ciclo VI como 100 , pode-se notar que as produtividades dos ciclos VII, VIII e IX aumentaram em 16\%, 7\% e 34\%, respectivamente. O ciclo $\mathrm{X}$ produziu $3 \%$ menos que o ciclo VI. Entretanto, a superioridade do ciclo X, em relação ao ciclo VI, pode ser notada em relação à BR 106 e pela comparação entre as progênies mais produtivas, que atingiram o limite de $8.541 \mathrm{~kg} / \mathrm{ha} \mathrm{no}$ ciclo X, na média de três locais, e $7.882 \mathrm{~kg} / \mathrm{ha}$ no ciclo VI, em um local.

As estimativas dos parâmetros genéticos das populações-base, em todos os ciclos de seleção, são mostradas na Tabela 3. As magnitudes dessas estimativas mantiveram-se constantes nos ciclos VI, VII e IX, registrando-se uma queda significativa nos

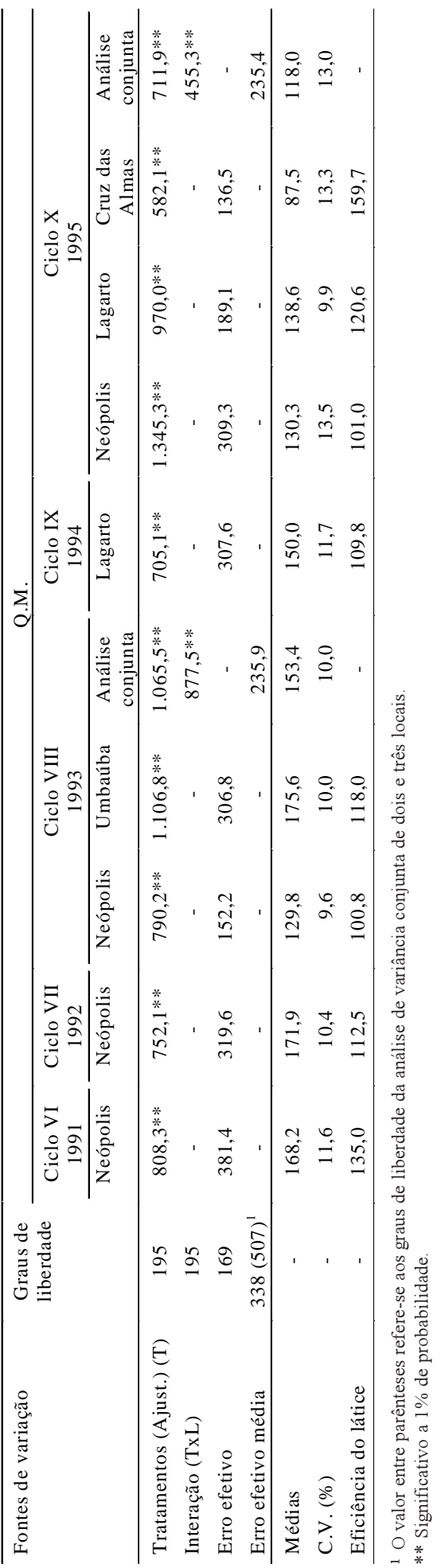


TABELA 2. Produções de espigas das progênies avaliadas e selecionadas, nos ciclos VI, VII, VIII, IX e X, e as testemunhas BR 106 e BR 201.

\begin{tabular}{|c|c|c|c|c|}
\hline \multirow[t]{2}{*}{ Ciclo } & \multirow[t]{2}{*}{ Material } & \multirow[t]{2}{*}{$\begin{array}{l}\text { Produtividades } \\
\text { médias (kg/ha) }\end{array}$} & \multicolumn{2}{|c|}{$\begin{array}{c}\text { Porcentagem em relação às } \\
\text { testemunhas }\end{array}$} \\
\hline & & & BR 106 & BR 201 \\
\hline \multirow[t]{5}{*}{ VI } & BR 106 & 6.907 & 100 & - \\
\hline & Médias das famílias avaliadas ${ }^{1}$ & 6.202 & 90 & - \\
\hline & Médias das famílias selecionadas ${ }^{2}$ & 7.398 & 107 & - \\
\hline & Família menos produtiva & 3.918 & 57 & - \\
\hline & Família mais produtiva & 7.882 & 114 & - \\
\hline \multirow[t]{6}{*}{ VII } & BR 106 & 6.123 & 100 & - \\
\hline & BR 201 & 7.492 & & 100 \\
\hline & Médias das famílias avaliadas ${ }^{1}$ & 7.216 & 118 & 96 \\
\hline & Médias das famílias selecionadas ${ }^{2}$ & 8.710 & 142 & 116 \\
\hline & Família menos produtiva & 3.761 & 61 & 50 \\
\hline & Família mais produtiva & 9,545 & 156 & 127 \\
\hline \multirow[t]{6}{*}{ VIII } & BR 106 & 7.771 & 100 & - \\
\hline & BR 201 & 7.537 & - & 100 \\
\hline & Médias das famílias avaliadas ${ }^{1}$ & 6.659 & 86 & 88 \\
\hline & Médias das famílias selecionadas ${ }^{2}$ & 8.605 & 111 & 114 \\
\hline & Família menos produtiva & 4.936 & 63 & 65 \\
\hline & Família mais produtiva & 8.619 & 111 & 114 \\
\hline \multirow[t]{6}{*}{ IX } & BR 106 & 6.533 & 100 & - \\
\hline & BR 201 & 7.772 & - & 100 \\
\hline & Médias das famílias avaliadas ${ }^{1}$ & 8.340 & 128 & 107 \\
\hline & Médias das famílias selecionadas ${ }^{2}$ & 10.160 & 156 & 131 \\
\hline & Família menos produtiva & 5.672 & 87 & 73 \\
\hline & Família mais produtiva & 11.933 & 191 & 154 \\
\hline \multirow[t]{6}{*}{$\mathrm{X}$} & BR 106 & 5.507 & 100 & - \\
\hline & BR 201 & 5.897 & - & 100 \\
\hline & Médias das famílias avaliadas ${ }^{1}$ & 6.032 & 110 & 102 \\
\hline & Médias das famílias selecionadas ${ }^{2}$ & 7.407 & 134 & 126 \\
\hline & Família menos produtiva & 3.930 & 71 & 67 \\
\hline & Família mais produtiva & 8.541 & 155 & 145 \\
\hline
\end{tabular}

1196 famílias avaliadas

20 famílias de meios-irmãos mais produtivas

ciclos VIII e X, em relação às análises de dois e três locais, respectivamente. Nestas, foi isolada a influência da interação progênies x locais. As estimativas da variância entre progênies de meios-irmãos não mostraram queda de variabilidade no decorrer dos ciclos de seleção, quando realizados em um só local, detectando-se, no entanto, uma redução acentuada quando a seleção foi realizada na média de dois e três locais. Fato semelhante foi observado por Aguiar (1986) e Pacheco (1987), com os ciclos original e primeiro da população cm CMS-39, em três e dois locais, respectivamente, e Carvalho et al. (1994, 1995, 1998a), com as cultivares BR 5028, BR 5033 e BR 5011, respectivamente, em dois locais.

Verificou-se, também, que a variação detectada na variância genética aditiva acompanhou a mostrada na variância genética entre progênies, registrando-se valores mais elevados nos ciclos VI, VII e IX, quando a seleção foi efetuada em apenas um local, superando os relatados por Paterniani (1968), Cunha 
TABELA 3. Estimativas obtidas em cada local e nas análises conjuntas, considerando o caráter peso de espigas: variância genética entre progênies $\left(\sigma_{p}^{2}\right)$; variância genética aditiva $\left(\sigma_{A}^{2}\right)$; variância da interação $\left(\sigma_{\mathrm{pxl}}^{2}\right)$; coeficiente de herdabilidade no sentido restrito considerando as médias de progênie $\left(h^{2} \mathrm{~m}\right)$; coeficiente de herdabilidade no sentido restrito considerando o indivíduo $\left(h^{2}\right)$; coeficiente de variação genética (CVg); índice de variação (b); ganhos genéticos (Gs) entre e dentro de progênies de meios-irmãos e Gs total por ciclo por ano.

\begin{tabular}{|c|c|c|c|c|c|c|c|c|c|c|c|c|}
\hline Ciclos & $\sigma_{p}^{2}$ & $\begin{array}{c}\sigma_{A}^{2} \\
-(g / \text { plant }\end{array}$ & $\begin{array}{c}\sigma_{p x l}^{2} \\
a^{2}-----\end{array}$ & $h^{2} m$ & $\begin{array}{c}\mathrm{h}^{2} \\
-(\%)\end{array}$ & $\mathrm{CVg}$ & b & $\begin{array}{l}\text { Gs entre } \\
\text { (g/planta) }\end{array}$ & $\begin{array}{c}\text { Gs entre } \\
(\%)\end{array}$ & $\begin{array}{l}\text { Gs dentro } \\
\text { (g/planta) }\end{array}$ & $\begin{array}{c}\text { Gs dentro } \\
(\%)\end{array}$ & $\begin{array}{c}\text { Gs total/ciclo/ano } \\
(\%)\end{array}$ \\
\hline VI & 213,5 & 854,0 & - & 52,8 & 21,2 & 12,0 & 1,0 & 18,6 & 11,1 & 8,9 & 5,3 & 16,4 \\
\hline VII & 216,2 & 865,0 & - & 57,5 & 25,3 & 8,6 & 0,8 & 19,6 & 11,4 & 9,7 & 5,6 & 17,0 \\
\hline VIII & 47,0 & 188,0 & 320,8 & 17,6 & 2,1 & 4,4 & 0,4 & 5,0 & 3,3 & 1,3 & 0,9 & 4,2 \\
\hline IX & 198,7 & 794,8 & - & 56,3 & 24,3 & 9,6 & 0,8 & 18,5 & 12,4 & 9,1 & 6,1 & 18,5 \\
\hline $\mathrm{X}$ & 42,8 & 171,1 & 109,9 & 36,0 & 3,7 & 5,5 & 0,4 & 6,9 & 5,8 & 1,7 & 1,5 & 7,3 \\
\hline
\end{tabular}

(1976), Crisóstomo (1977), Miranda Filho (1977), Ramalho (1977), Miranda Filho (1979), Aguiar (1986), Carvalho et al. (1994, 1995, 1998a). As estimativas obtidas a partir das análises conjuntas, nos ciclos VIII e X, estão compatíveis com as relatadas por Aguiar (1986), Pacheco (1987) e Carvalho et al. (1998a). Segundo Paterniani (1968), é do máximo interesse que a variância genética aditiva permaneça tão alta quanto possível, para permitir progressos substanciais por seleção. O autor comenta, ainda, que esse método de seleção reduz muito essa variância no primeiro ciclo de seleção, mas, apesar dessa redução, no decorrer dos ciclos de seleção, têm-se observado ganhos altamente satisfatórios, a exemplo dos obtidos por Webel \& Lonquist (1967), citados por Paterniani (1968), o qual foi de $9,4 \%$ ao ano, em quatro ciclos de seleção.

As estimativas da variância da interação progênie x local, nos ciclos VIII e X, foram $58,0 \%$ e $156 \%$ maiores que as respectivas estimativas das variâncias genéticas entre progênies, o que evidencia a grande divergência do comportamento das progênies entre os locais (Tabela 3). Hallauer \& Miranda Filho (1988) comentam que este componente da variância pode atingir mais de $50 \%$ do valor da estimativa da variância genética entre progênies e que as estimativas de parâmetros genéticos e fenotípicos obtidos em apenas um local são superestimados, em razão da existência do componente de variação resultante da interação progênies x local, que não pode ser isolado. Paterniani (1968) salienta que após sucessivos ciclos de seleção o material deverá tornar-se, progressivamente, mais uniforme, e, também, deverá haver menor interação genótipo $\mathrm{x}$ ambiente.
Os coeficientes de herdabilidade no sentido restrito, na média de progênies de meios-irmãos $\left(\mathrm{h}^{2} \mathrm{~m}\right)$ superaram os registrados na seleção massal $\left(h^{2}\right), 0$ que indica que a seleção com progênies de meiosirmãos deve ser mais eficiente que a seleção massal; isto concorda com Aguiar (1986), Pacheco (1987) e Carvalho et al. (1994, 1995, 1998a, 1998b). Deve-se salientar que os valores mais altos foram encontrados nos ciclos VI, VII e IX, realizados em um só local, sendo as estimativas dos coeficientes de herdabilidade no sentido restrito $\left(\mathrm{h}^{2} \mathrm{~m}\right)$ compatíveis com as registradas por Rissi (1980), com a população Piranão B (70,73\%), e por Lordello (1982), com a população Piranão VF-1 (69,18\%). Os valores dos coeficientes de variação genética refletem uma boa variação entre as progênies em todos os ciclos, apesar de ser relevante no âmbito local. Os coeficientes b retratam uma situação mais favorável para a seleção no âmbito local, sendo os valores mostrados superiores aos relatados por Ramalho (1977), Aguiar (1986), Pacheco (1987) e Carvalho et al. (1994, 1995, 1998a).

Nos ciclos VI, VII e IX, os ganhos estimados com a seleção entre e dentro das progênies foram, respectivamente, $11,1 \%$ e $5,3 \%$, totalizando $16,4 \%$ (ciclo VI), 11,4\% e 5,6\%, totalizando 17,0\% (ciclo VII) e $12,4 \%$ e $6,1 \%$, totalizando $18,5 \%$ (ciclo IX). Essas estimativas são superiores às relatadas por Paterniani (1968), Cunha (1976) e Lima (1977), e inferiores às registradas por Lordello (1982). Nos ciclos VIII e X, nas médias dos locais, os ganhos preditos entre e dentro de progênies foram, respectivamente, de 3,3\% e $0,9 \%$, totalizando $4,2 \%$ (ciclo VIII) e $5,8 \%$ e $1,5 \%$, 
totalizando 7,3\% (ciclo X), sendo compatíveis com os obtidos por Aguiar (1986) e Pacheco (1987), e superados pelos encontrados por Carvalho et al. (1994, 1995, 1998a, 1998b). As diferenças nos ganhos esperados, em relação aos ciclos VIII e X, devem-se, principalmente, ao fato de os ciclos VI, VII e IX terem sido realizados em apenas um local, capitalizando a interação progênies x locais. Nota-se que os ganhos estimados pela seleção entre progênies foram superiores em relação aos registrados por seleção massal. Na média dos vários ciclos constatou-se um ganho médio estimado pela seleção entre famílias, de $8,8 \%$, e pela seleção massal, de $3,88 \%$, totalizando um ganho médio por ciclo de $12,68 \%$, evidenciando maior contribuição da seleção entre progênies de meios-irmãos. Considerando a variabilidade detectada a partir das estimativas dos parâmetros genéticos e o fato de essa cultivar apresentar alto potencial para produtividade, acredita-se que substanciais progressos serão obtidos com a continuidade do programa de seleção.

\section{CONCLUSÕES}

1. A alta variabilidade genética da cultivar BR 5011Sertanejo e as elevadas médias de produtividade das progênies são indicadoras de grande potencial genético desse material.

2. A estimativa da variância da interação progênies $\mathrm{x}$ local evidencia a importância de se realizar a seleção em mais de um local, para melhorar a adaptabilidade da população, a eficiência do processo seletivo, e permitir a obtenção de estimativas dos componentes da variância genética não inflacionadas por essa interação.

3. Após a realização de dez ciclos de seleção, a cultivar BR 5011-Sertanejo ainda apresenta uma quantidade apreciável de variabilidade genética.

\section{REFERÊNCIAS}

AGUIAR, P.A. de Avaliação de progênies de meiosirmãos de milho CMS-39 em diferentes condições de ambientes. Lavras : ESAL, 1986. 68p. Dissertação de Mestrado.
CARVALHO, H.W.L. de; SERPA, J.E.S. Comportamento de cultivares de milho no Estado de Sergipe: ensaios estaduais de rendimentos, 1982, 1984 e 1985 Aracaju : Embrapa-CNPCo, 1987. 32p. (EmbrapaCNPCo. Boletim de Pesquisa, 1).

CARVALHO, H.W.L. de; MAGNAVACA, R.; LEAL, M. de L. da S. Estabilidade de produção de cultivares de milho no Estado de Sergipe. Pesquisa Agropecuária Brasileira, Brasília, v.27, n.7, p.1073-1082, jul. 1992.

CARVALHO, H.W.L. de; PACHECO, C.A.P.; SANTOS, M.X. dos; GAMA, E.E.G.; MAGNAVACA, R. Potencial genético da população de milho (Zea mays L. 'CMS-33') para fins de melhoramento no Nordeste brasileiro. Ciência e Prática, Lavras, v.19, n.1, p.37-42, 1995.

CARVALHO, H.W.L. de; PACHECO, C.A.P.; SANTOS, M.X. dos; GAMA, E.E.G.; MAGNAVACA, R. Três ciclos de seleção entre e dentro de famílias de meiosirmãos na população de milho BR 5011 no Nordeste brasileiro. Pesquisa Agropecuária Brasileira, Brasília, v.33, n.5, p.713-720, maio 1998a

CARVALHO, H.W.L. de; PACHECO, C.A.P.; SANTOS, M.X. dos; GAMA, E.E.G.; MAGNAVACA, R. Três ciclos de seleção entre e dentro de famílias de meiosirmãos na população de milho BR 5028-São Francisco, no Nordeste brasileiro. Pesquisa Agropecuária Brasileira, Brasília, v.29, n.11, p.1721-1733, nov. 1994.

CARVALHO, H.W.L. de; SANTOS, M.X. dos; LEAL, M. de L. da S.; PACHECO, C.A.P. Melhoramento genético da cultivar de milho BR 5028-São Francisco no Nordeste brasileiro. Pesquisa Agropecuária Brasileira, Brasília, v.33, n.4, p.441-448, abr. 1998b.

CRISÓSTOMO, J.R. Estimação de parâmetros genéticos em duas populações de milho (Zea mays $\mathbf{L}$.) Piracicaba : ESALQ, 1977. 70p. Dissertação de Mestrado

CUNHA, M.A.P. da. Seleção entre e dentro de famílias de meios-irmãos de milho (Zea mays L.) ESALQ VD-2. Piracicaba : ESALQ, 1976. 84p. Dissertação de Mestrado.

GAMA, E.E.G.; NASPOLINI FILHO, V.; VIANNA, R.T; MAGNAVACA, R. Melhoramento da população CMS-11 através do método de seleção recorrente. Relatório Técnico Anual do CNPMS, Sete Lagoas, v.3, p.21-132, 1986.

Pesq. agropec. bras., Brasília, v.35, n.6, p.1169-1176, jun. 2000 
HALLAUER, A.R.; MIRANDA FILHO, J.B Quantitative genetics in maize breeding. 2.ed. Ames : Iowa State University Press, 1988. 468p.

LIMA, M. Seleção entre e dentro de famílias de meios-irmãos na população de milho (Zea mays $\mathrm{L}$.) ESALQ HV-1. Piracicaba : ESALQ, 1977. 71p Dissertação de Mestrado.

LORDELLO, J.A.C. Parâmetros genéticos das populações de milho Piranão VD-2 e Piranão VF-1. Piracicaba : ESALQ, 1982. 70p. Dissertação de Mestrado

MIRANDA FILHO, J.B. Avaliação de famílias de meios-irmãos na população de milho ESALQ PB-1 Piracicaba : ESALQ, 1977. p.90-94. (Relatório Técnico-Científico, 11)

MIRANDA FILHO, J.B. Avaliação de famílias de meios-irmãos do segundo ciclo de seleção da população ESALQ PB-1 de milho. Piracicaba : ESALQ, 1979. p.149-158. (Relatório Técnico-Científico, 13).

MIRANDA FILHO, J.B. Cruzamento dialélicos e síntese de composto de milho (Zea mays $\mathbf{L}$.) com ênfase na produtividade e no porte da planta. Piracicaba : ESALQ, 1974. 116p. Dissertação de Mestrado.

PACHECO, C.A.P. Avaliação de progênies de meiosirmãos da população de milho CMS-39 em diferentes condições de ambientes: $2^{\circ}$ ciclo de seleção. Lavras : ESAL, 1987. 100p. Dissertação de Mestrado
PATERNIANI, E. Avaliação de métodos de seleção entre e dentro de famílias de meios-irmãos no melhoramento de milho (Zea mays L.) Piracicaba : ESALQ, 1968. 92p. Dissertação de Mestrado

PATERNIANI, E. Selection among and within half-sib families in a Brazilian population of mayze (Zea mays L.). Crop Science, Madison, v.7, n.3, p.212216,1967

PIMENTEL-GOMES, F. Curso de Estatística experimental. 8.ed. São Paulo : Nobel, 1978. 450p.

RAMALHO, M.A.P. Eficiência relativa de alguns progressos de seleção intrapopulacional no milho baseados em famílias não endógamas. Piracicaba : ESALQ, 1977. 122p. Dissertação de Mestrado.

RISSI, R. Estimação de parâmetros genéticos em duas subpopulações de cultivar de milho (Zea mays $\mathbf{L}$.) Piranão. Piracicaba : ESALQ, 1980. 81p. Dissertação de Mestrado.

VENCOVSKY, R. Herança quantitativa. In: PATERNIANI, E. (Ed.). Melhoramento e produção de milho no Brasil. Piracicaba : ESALQ, 1978. p.122-201.

VIANNA, R.T.; SILVA, J.C. Comparação de três métodos estatísticos de análise de variância em experimentos em "látice" em milho (Zea mays L.). Experientiae, Viçosa, v.24, p.21-41, 1978

WINKLER, E.I.G. Seleção entre e dentro de famílias de meios-irmãos no milho (Zea mays $L$.) composto dentado branco. Piracicaba : ESALQ, 1977. 54p. Dissertação de Mestrado. 